\title{
Commentary: Two ounces of prevention does not equal a pound of cure
}

\author{
J. Awori Hayanga, MD, Percy Buenaventura, MD, and Ghulam Abbas, MD, MHCM, FACS
}

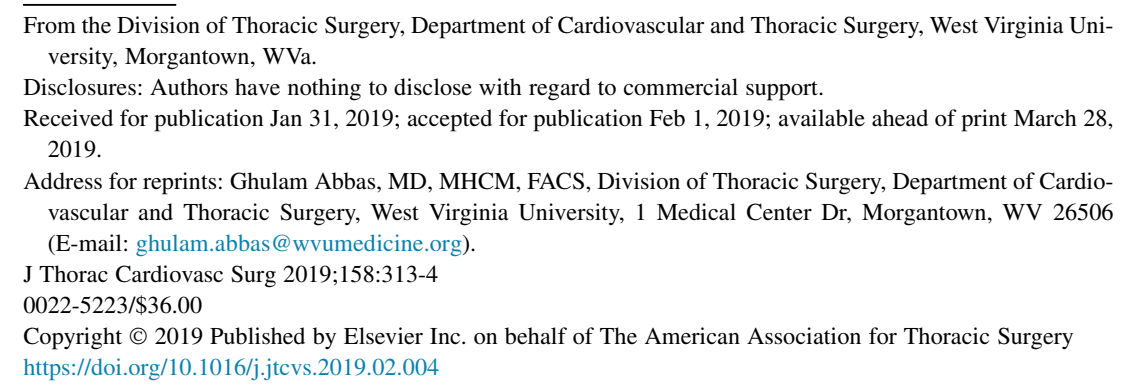

In this issue of the Journal, Tisdale and colleagues ${ }^{1}$ report the results from their retrospective cohort study in which they analyzed propensity-matched data pertaining to 110 postesophagectomy patients who received prophylactic amiodarone compared with 110 others who served as a control group. The amiodarone prophylaxis was started with induction of anesthesia and continued until postoperative day 4 , with a cumulative dose of $42 \mathrm{~g}$. They report that the use of amiodarone led to a $55 \%$ reduction in the incidence of atrial fibrillation in the study group. This is significant, because the incidence of the atrial fibrillation was also low in the control group (in comparison with larger esophagectomy series), perhaps because of the liberal use of $\beta$-blockers and calcium-channel blockers in the perioperative period. This lower incidence of atrial fibrillation in the study group failed, however, to translate into shorter stay or better outcomes. Surprisingly, the incidence of home discharge with atrial fibrillation was higher in the amiodarone group $(17.6 \%)$ than in the control group $(9.4 \%)$. Most of the patients in the amiodarone group who had developed atrial fibrillation were continued on amiodarone for treatment, leading to a cumulative dose greater than $42 \mathrm{~g}$. The incidences of hypotension requiring treatment with fluid bolus and vasopressors and of prolonged corrected QT interval were higher in the amiodarone group.

The incidence of atrial fibrillation, with its attendant needs for anticoagulation and escalation of resource intensity, constitutes an important postsurgical concern. ${ }^{2}$ As such, attention paid to the mitigation of this problem in contemporary practice has included prophylactic $\beta$-blockade, calciumchannel blockade, and administration of amiodarone..$^{3-5}$ The only randomized trial on the use of amiodarone in postesophagectomy patients showed possible benefit and became the basis of the consensus statement suggesting amiodarone prophylaxis after thoracic procedures. ${ }^{6,7}$

Tisdale and colleagues ${ }^{1}$ attempted to minimize bias and confounders through the application of propensity

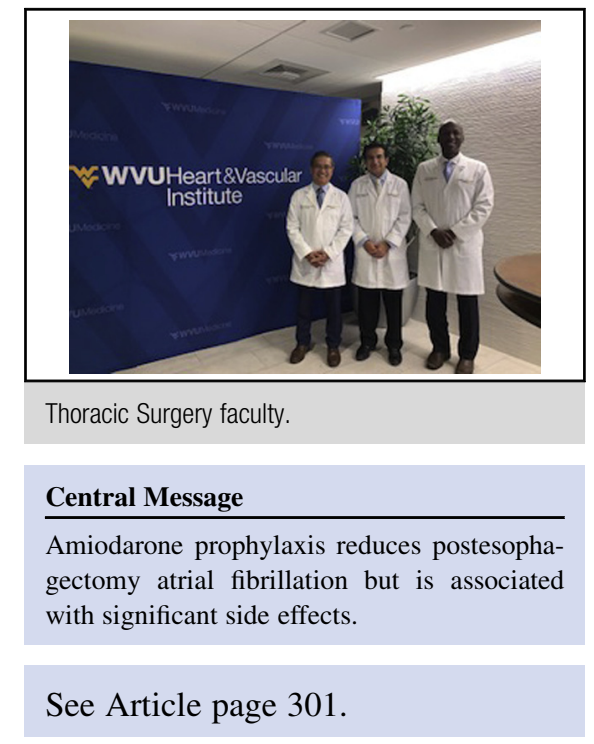

matching. Other factors that may influence atrial fibrillation, however, were either not matched in this study or bundled with another factor, such as chemotherapy with or without radiation. Intrathoracic adhesions, extent of mediastinal dissection, thoracotomy or thoracoscopy, and postoperative complications such as anastomotic leak are important culprits for postesophagectomy atrial fibrillation and were not matched, adding to the limitations of this study.

The overall message of Tisdale and colleagues ${ }^{1}$ drives the impetus for continued appraisal of processes of care and of clinical algorithms that evaluate, in real time, what care is being rendered. Notably, patients in the amiodarone group who had atrial fibrillation develop and were continued on the amiodarone for the treatment of atrial fibrillation ended up with a higher dose (more than 2 ounces), leading to significant side effects without the desired treatment effect or cure. Surgeons should evaluate the benefits associated with the prophylactic use of amiodarone in any patient to make sure that they outweigh the risks.

\section{References}

1. Tisdale JE, Jaynes HA, Watson MR, Corya AL, Shen C, Kesler KA. Amiodarone for prevention of atrial fibrillation following esophagectomy. J Thorac Cardiovasc Surg. 2019:158:301-10.e1.

2. Melduni RM, Schaff HV, Bailey KR, Cha SS, Ammash NM, Seward JB, et al. Implications of new-onset atrial fibrillation after cardiac surgery on long-term prognosis: a community-based study. Am Heart J. 2015;170:659-68. 
3. Riber LP, Larsen TB, Christensen TD. Postoperative atrial fibrillation prophylaxis after lung surgery: systematic review and meta-analysis. Ann Thorac Surg. 2014; 98:1989-97.

4. Kolokotroni SM, Toufektzian L, Harling L, Billè A. In patients undergoing lung resection is it safe to administer amiodarone either as prophylaxis or treatment of atrial fibrillation? Interact Cardiovasc Thorac Surg. 2017:24:783-8.

5. Tisdale JT, Wroblewski HA, Wall DS, Rieger KM, Hammoud ZT, Young JV, et al. A randomized, controlled study of amiodarone for prevention of atrial fibrillation after transthoracic esophagectomy. J Thorac Cardiovasc Surg. 2010;140:45-51.
6. Fernando HC, Jaklitsch MT, Walsh GL, Tisdale JE, Bridges CD, Mitchell JD, et al. The Society of Thoracic Surgeons practice guideline on the prophylaxis and management of atrial fibrillation associated with general thoracic surgery: executive summary. Ann Thorac Surg. 2011;92:1144-52.

7. Frendl G, Sodickson AC, Chung MK, Waldo AL, Gersh BJ, Tisdale JE, et al; American Association for Thoracic Surgery. 2014 AATS guidelines for the prevention and management of perioperative atrial fibrillation and flutter for thoracic surgical procedures: executive summary. J Thorac Cardiovasc Surg. 2014;148:772-91. 